\title{
UPPER AIRWAY CONTROL IN AIRWAY DEFENSE
}

\author{
${ }^{*}$ Poliacek $\mathrm{I}^{1}$, Simera $\mathbf{M}^{1}$, Calkovsky $\mathrm{V}^{2}$, Jakus $\mathrm{J}^{1}$.
}

Comenius University in Bratislava, Jessenius Faculty of Medicine in Martin and University Hospital, Martin, Slovakia ${ }^{1}$ Institute of Medical Biophysics, ${ }^{2}$ Clinic of Otorhinolaryngology and Head and Neck Surgery

\section{A b s t r a c t}

Upper airways (UA) are an organic component of the respiratory tract, they serve to respiration, respiratory tract protection and defense, phonation, deglutition, etc. The functions of UA are regulated by motor control of the oral, pharyngeal, and laryngeal muscles.

UA typically stiffen and widen during inspiration mainly due to the activation of the alae nasi, genioglossus m., pharyngeal dilators, and laryngeal abductors. These and other UA muscles (e.g. laryngeal and pharyngeal constrictors) may express varoius activity patterns, actively shaping UA depending on species, arousal, respiratory drive, and behavior being executed. E.g. during coughing and sneezing laryngeal movement consists of abductions in inspiration and expiration and adductions in compression and subsequent constriction phase. The cricopharyngeus $\mathrm{m}$., in cough expiration the superior pharyngeal constrictor and in the sneeze expiration the styloglossus and levator veli palatini $\mathrm{m}$. are activated. Unlike in breathing or coughing, where UA serve to respiration-protection-defense, the pharyngeal phase of swallowing is essentially made by the coordinated action of a number of UA muscles.

Motoneurons driving the UA muscles are located primarily in the hypoglossal and ambigual nuclei. Motor pattern of individual motoneuronal pools is determined by activation-inhibition-modulation from pre-motoneurons and other upstream neurons of the reflex circuits. Laryngeal and hypoglossal nerve activity is during breathing under command of respiratory central pattern generator. UA muscles are driven in inspiration primarily from augmenting, less from decrementing and constant inspiratory neurons. Number of additional inputs is involved in UA regulation during expirations and other motor behaviors. Anatomical and functional studies pointed out number of brainstem areas, such as the regions of solitary tract nucleus, hypoglossal ncl., trigeminal ncl., lateral tegmental field, raphé, the ventral and ventrolateral medulla, pontine parabrachial region, etc. with neurons related to UA motor control.

Abundant connectivity of the neuronal network that controls UA patency employs almost all kind of receptors and neurotransmitter/neuromodulator systems. Among large number of diseases and disorders that relate to UA, primarily cholinergic, norepinephrine, and serotonergic tonic drives are implicated in those resulted from the reduced UA tone. Pharmacological and frequently simple surgical interventions may improve these conditions (snore, obturation) in patients. Recently, besides medicinal treatment, conditional procedures incorporating an exercise and practice, stimulation of appropriate afferent pathways, and combining reflex responses may offer promising therapies.

Key words: upper airway, airways defense, central control, cough, swallow

\section{INTRODUCTION}

This paper summarizes substantial knowledge upon the function and control of upper airways during the defensive airway motor behaviors. Integrating our own experimental data with current research findings may improve our understanding of upper airways performance under the physiological and pathological conditions.

Upper airways (UA) represent an organic structural and functional component of the respiratory tract. UA serve to respiration, respiratory tract protection and defense, phonation, deglutition, etc. Essential regulatory functions of UA represent changes in the airway resistance and its appropriate "shaping" up to the complete close. These functions are executed by the oral, pharyngeal, and laryngeal structures and regulated by motor control of the oral, pharyngeal, and laryngeal „valve“ muscles. Main muscles included in respiratory and/or

\footnotetext{
A d d r e s s or corres pond en c e:

Poliacek Ivan,Dr,PhD. Comenius University in Bratislava, Jessenius Faculty of Medicine in Martin, Institute of Medical Biophysics, Mala Hora 4, 03601 Martin, Phone: +421 432633 444, Fax: +421 434238299 ;

e-mail: poliacek@jfmed.uniba.sk
} 
airway defensive functions are e.g. alae nasi muscles, tensor and levator veli palatini, stylopharyngeus, styloglossus, geniohyoid, genioglossus, thyropharyngeus, cricopharyngeus, myohyoid, thyrohyoid, and intrinsic laryngeal muscles from them primarily posterior cricoarytenoid (PCA) and thyroarytenoid m. (Iscoe 1988; Zoungrana et al. 1997; Satoh et al. 1998; Pitts et al. 2013).

\section{RESPIRATORY FUNCTION OF UPPER AIRWAYS}

UA provide approximately $1 / 2$ of the airway resistance, $2 / 3$ with nasal breathing in humans (VanLunteren and Strohl 1986). The main component regulating the UA resistance is the larynx (Iscoe 1988). UA typically stiffen and widen during quiet inspiration mainly due to the inspiratory (I) activation of the alae nasi muscles, genioglossus, pharyngeal dilators, and laryngeal abductor PCA (Fig. 1; Brancatisano et al. 1986; Iscoe 1988; Shi et al. 1998; Saboisky et al. 2007; Sawczuk and Mosier 2001).

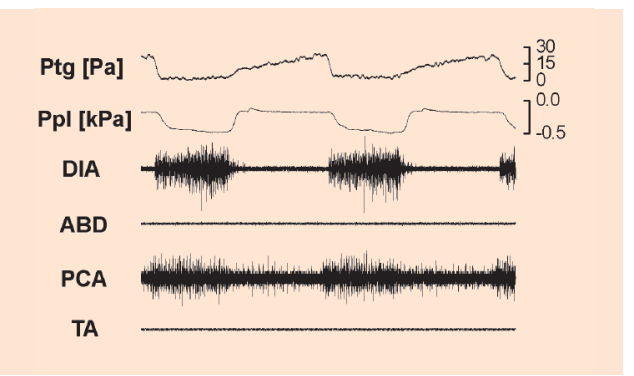

Fig. 1 Inspiratory activation of laryngeal abductor - posterior cricoarytenoid muscle (PCA) in anesthetized cat, resulting in changes of laryngeal resistance (representing the waveform of transglottic pressure - Ptg). Note, that PCA activation slightly precedes that of the diaphragm (DIA) and concomitant alterations of pleural pressure (Ppl). During eupnea there is no activity of abdominal muscles $(\mathrm{ABD})$ and laryngeal adductor thyroarytenoid muscle (TA). With increased ventilation late expiratory $\mathrm{ABD}$ and early expiratory TA activities may occur.

Narrowing of UA during quiet expiration results from reduced activity of dilators and activation of laryngeal and pharyngeal constrictors (Sherrey and Megirian 1975; Hairston and Sauerland 1981; Iscoe 1988; Poliacek et al. 2003). Thus, tonic activity of some UA muscles (e.g. PCA; Fig. 1; laryngeal adductors, or cricopharyngeus) and/or their expiratory (E) modulation (e.g. laryngeal adductor thyroarytenoid, thyropharyngeus, superior pharyngeal constrictor m.) occurs as well, providing an active shaping of UA in expiration, depending on species, anesthetic, and respiratory drive (Iscoe 1988; Perlman 2006; Rose et al. 2011; Pitts et al. 2013).

Afferent feedback from a variety of airway, pulmonary, and muscle receptors contributes significantly to the control of UA. There are considerable differences in muscle activation during oral vs. nasal breathing e.g. for alae nasi muscles (Shi et al. 1998). Hypoxia and hypercapnia states, as well as other conditions that enhance breathing, modulate activity of many UA muscles resulting in substantial changes in the airway resistance and airflow (Brancatisano et al. 1986; Iscoe 1988; Mezzanotte et al. 1992). Similarly, reduced breathing e.g. during sleep, anesthesia, anatomical and functional irregularities can modulate the UA patency, usually reversely than upon the hyperpnea states (Kuna et al. 1997; Saboisky et al. 2007; Nishino 2013). 


\section{UPPER AIRWAYS DURING THE AIRWAY DEFENSE}

Primary component of the respiratory tract protection is laryngoconstriction. Complete closure of the larynx results in halted airflow, thus preventing the penetration of any material including irritant gases into the lower airways. The duration of the apneic pause is limited by necessity for breathing.

During defensive airway reflexes such as coughing, sneezing, sniff-like aspiration reflex, expiration reflex, swallowing the laryngeal, pharyngeal, but also lingual muscles may provide vigourous highly coordinated action resulting in appropriate changes in UA calibre and tonus. Laryngeal movement consists of abductions during I and E phase and adductions in compression and subsequent constriction phase during cough (Fig. 2 and 3) and sneeze (Korpáš and Tomori 1979; Shiba et al. 1999; Poliacek et al. 2003). Simpler patterns at least for some motoneurons were found in decerebrate animals (Gestreau et al. 2000; Baekey et al. 2001). During all cough period the cricopharyngeus m., in E phase the superior pharyngeal constrictor (Satoh et al. 1998) are activated and thyropharyngeus $\mathrm{m}$. is suppressed at least in cat (Pitts et al. 2013). In the sneezing expiration also styloglossus, and levator veli palatini m. are activated (Satoh et al. 1998; Simera et al. 2015).

Corresponding patterns in activities of laryngeal muscles were found in the expiration and aspiration reflexes consisting of laryngeal adduction interrupted and overlayed by the shortlasting abduction allowing the airflow (Poliacek et al. 2003, 2005). In general, there is higher degree of UA stiffening in defensive airway behaviors than that in quiet breathing (Korpas and Tomori 1979; Sant.Ambrogio et al. 1997; Poliacek et al. 2003)

Unlike in breathing or coughing, where UA serve to respiration-protection-defense, the pharyngeal phase of swallowing is essentially made by the coordinated action of a number of UA muscles (Doty and Bosma 1956; Miller 2008, Pitts et al. 2013). The palatum closes the velopharyngeal isthmus, larynx is fully closed by its adduction and by epiglottis and is elevated under the base of tongue. Posterior tongue movement moves the bolus into esophagus and subsequent contraction of pharyngeal constrictors clears the pharynx (Ertekin and Aydoglu 2003). During this oro-pharyngeal phase of swallowing progressively and/or simultaneously majority of the pharyngeal and lingual muscles e.g. mylohyoid, geniohyoid, palatopharyngeus, styloglossus, levator veli palatini, thyropharyngeus m., and laryngeal adductors are vigorously activated with an early relaxation followed by the activation of the cricopharyngeus (upper esophageal sphincter) all performed in an orderly fashion (Fig. 3, Doty and Bosma 1956; Jean 2001; Sawczuk and Mosier 2001; Ertekin and Aydoglu 2003, Miller 2008, Pitts et al. 2013).

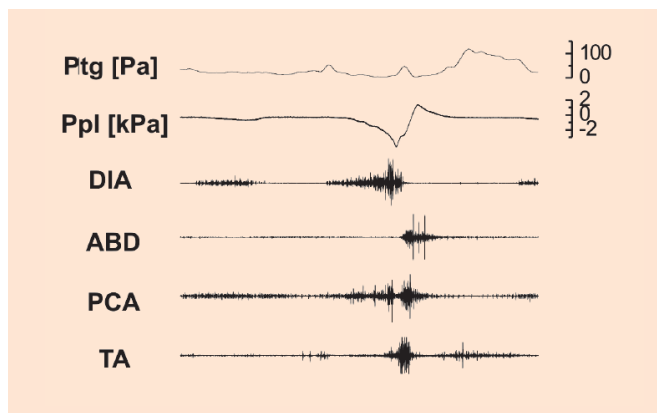

Fig. 2 Laryngeal control of the airflow resistance (represented by the waveform of transglottic pressure - Ptg) during tracheobronchial cough in cat. Successive cough related activities of diaphragm (DIA) and abdominal muscles (ABD) producing concomitant changes in pleural pressure (Ppl) are accompanied by inspiratory and expiratory activation of posterior cricoarytenoid m. (PCA) and compressive and late activation of thyroarytenoid $\mathrm{m}$. (TA) producing 2 cough related decreases and 2 cough related increases in Ptg. 


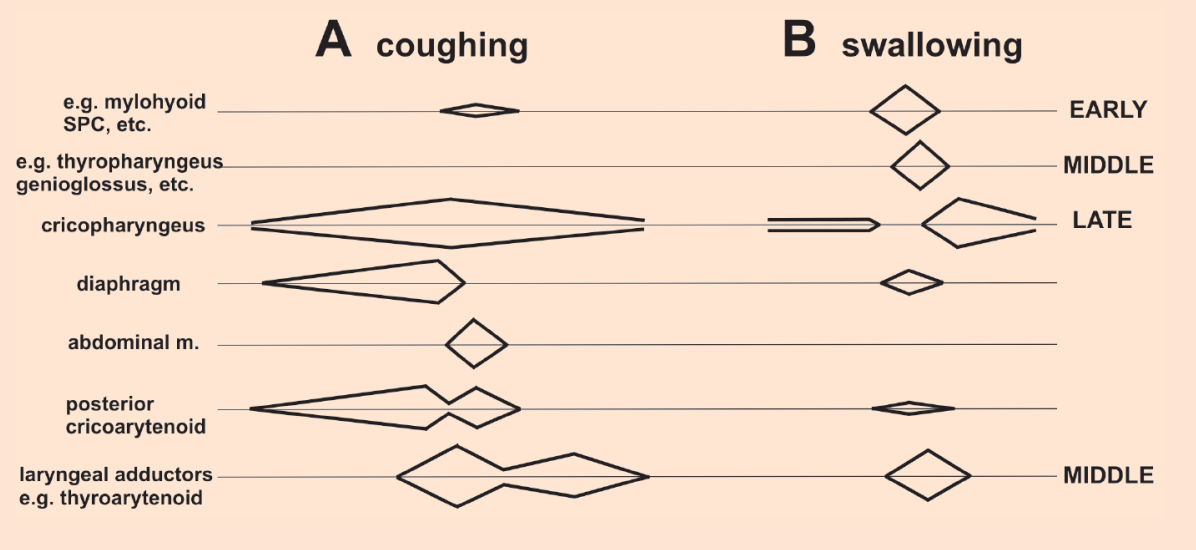

Fig. 3 Scheme of UA action during coughing (panel A) and swallowing (panel B).

A: Cough is produced by successive activities of diaphragm (DIA) and abdominal m. (ABD). Some oropharyngeal muscles are rather inactive (thyropharyngeus, styloglossus, genioglossus m. etc.) the others (e.g. superior pharyngeal constrictor - SPC) express some expiratory activity during coughing. Laryngeal pattern consists of 2 activations of posterior cricoarytenoid and 2 activations of thyroarytenoid m. (see Fig. 2). For the time relations see Poliacek et al. (2003). Cricopharyngeus m. (upper esophageal sphincter) is active during the whole cough cycle with the maximum at the inspiratoryexpiratory transition.

B: Oro-pharyngeal phase of swallowing is produced mainly by lingual, pharyngeal, and laryngeal muscles. Leading complex of muscles (myohyoid, styloglossus m. etc.) and with the delay no longer than $50 \mathrm{~ms}$ (palatopharyngeus $\mathrm{m}$. etc.) are activated (EARLY) providing a laryngeal elevation, pharyngeal constriction, and bolus movement towards the esophagus. With the delay of $100 \mathrm{~ms}$ and more inferior pharyngeal constrictor $\mathrm{m}$. (thyropharyngeus and also geniohyoid $\mathrm{m}$. etc.) and laryngeal constrictors (thyroarytenoid m. etc.) are activated (MIDDLE). Coordinated action of e.g. thyropharyngeus m., laryngeal constrictors, and cricopharyngeus $\mathrm{m}$. (upper esophageal sphincter) with an early relaxation of the esophagus followed by the subsequent contraction of cricopharyngeus m. (LATE) guides the bolus to the esophagus, thus prevents the reflux of bolus. The burst of DIA activity during swallowing represent the "swallow breath“ - schluckatmung.

\section{MOTOR DRIVE TO THE UPPER AIRWAYS}

Motoneurons driving the UA muscles are located primarily in the hypoglossal (HgN; geniohyoid, styloglossus m., etc.) and ambigual nuclei (Fig. 4; levator veli palatini, pharyngeal constrictors, intrinsic laryngeal muscles, cricopharyngeus m., etc.), but also in trigeminal (mylohyoid m., etc.) and facial nuclei (Iscoe 1988; Jean 2001; Zougrana et al. 1997).

There is a large variation in the activity of motoneurons driving distinct UA muscles and the variability in the activation of individual muscles during various behaviors (Shiba et al. 1999; Gestreau et al. 2000; 2005; Poliacek et al. 2003; Pitts et al. 2013). However, significant differences in the firing patterns of individual motoneurons that supply one particular UA muscle may occur even during one behavior (Shiba et al. 1999; Roda et al. 2002; Gestreau et al. 2000; 2005).

The activity patterns of majority of motoneurons correspond to the related muscle activation, e.g. during eupnea I pattern of the discharge in the recurrent laryngeal (branch of the vagus n. supplying the intrinsic laryngeal muscles) and hypoglossal nerves represent main- 
ly PCA and genioglossus m. motoneuronal activities. Some thyroarytenoid motoneurons are activated during cough in the compression phase and then again during the post-constriction (Stransky et al. 1976; Poliacek et al. 2003), while others are activated over all cough cycle (Shiba et al. 1999; Baekey et al. 2001). Hypoglossal motoneurons, that are quiescent or activated during eupneic inspiration, may depolarize or hyperpolarize or even express a depolarization immediately followed by an after-hyperpolarization during swallowing. Some hypoglossal motoneurons hyperpolarize during all active cough cycle with immediate depolarization afterwards, others hyperpolarize in I and depolarize in $\mathrm{E}$ phase of cough (Roda et al. 2002; Gestreau et al. 2005). E laryngeal motoneurons depolarize during pharyngeal phase of swallowing, I laryngeal motoneurons may be either hyperpolarized or depolarized (Zoungrana et al. 1997; Suzuki et al. 2010).

Motor pattern of individual motoneuronal pools is determined by activation-inhibitionmodulation from pre-motoneurons and other upstream neurons of the reflex circuits. Some of these units are directly or vicariously responsive to various peripheral feedbacks (Bailey and Fregosi 2006; Spearman et al. 2014; Pitts et al. 2015). Many of neurons regulating UA motor output are involved in the control of primary behaviors e.g. breathing, coughing, vomiting, etc., in order to provide coordination of airway functions with the needs of particular behavior (Jean 2001; Jakus et al. 2004; 2008; Poliacek et al. 2005; Pitts et al. 2013).

\section{BRAINSTEM CONTROL OF UPPER AIRWAY MOTOR OUTPUT}

Majority of neuronal circuits controlling UA (at least during their autonomic and reflex function) are located in the brainstem. These circuits include respiratory related, non-respiratory related, and among them specific behavior related neurons. According to the position of neurons in the reflex arc, there are motoneurons, pre-motoneurons, pattern generating cells, and modulatory units, which include the 2nd order neurons receiving various peripheral inputs, inhibitory neurons that are components of behavior coordinating circuits (reciprocal inhibition e.g. for swallow and breathing or swallow and cough), and the pathways from higher brain levels (Jean 2001; Sawczuk and Mosier 2001; Jakus et al. 2004; Nishino 2013).

An adequate understanding of the UA central control and its complex performance largely depends on sufficient answers to the following questions: 1) Where are located neurons driving (directly or undirectly) motoneurons of UA muscles? 2) What is the connectivity of these neurons and how do they shape the activity of UA motoneurons during various behaviors? 3) Which mechanisms are employed in activation / inhbition that comes from these central circuits controlling UA patency?

Anatomical and functional studies pointed out multiple brainstem areas with various density of neurons connected to or related to UA motor control (Fig. 4): the solitary tract nucleus (NTS), dorsal reticular formation near the HgN, lateral tegmental field represented by the parvocellular and other reticular nuclei, spinal trigeminal ncl., paratrigeminal region, area postrema, retroambigual area, caudal raphé, the ventral and ventrolateral medulla (including retrofacial, parafacial, and paraambigual area), parabrachial region of the pons including Kölliker-Fuse ncl., the subcoeruleus region, pontine trigeminal nuclei, ncl. caudalis and ventralis, ventromedial tegmentum, lateral paragigantocellular region, and higher brain levels including periaqueductal grey (e.g. Fay and Norgren 1997; Jean 2001; Waldbaum et al. 2001; Jakus et al. 2004; Boers et al. 2005; Gestreau et al. 2005). Activation of neuronal populations in these areas vary depending on the momentary action of UA and the behavior induced, e.g. Fos labeling, indicating neuronal activation, related to laryngeal adduction was limited to NTS, lateral tegmental field, area postrema, and ambigual ncl., meanwhile laryngeal stimulation that induced expiration reflex induced Fos detectable activation in additional regions of retroambigual ncl., alaminar spinal trigeminal ncl. retrofacial and lateral reticular ncl., and area of pontine respiratory group. Basic view at the functional map 
of neuronal distribution during tracheobronchial cough (Jakus et al. 2008) and other airways defensive behaviors summarizes the Fos study of Poliacek et al. (2008).

\section{PRIMARY DRIVE TO MOTONEURONS OF UPPER AIRWAYS}

Laryngeal and hypoglossal nerve activity is during breathing under the command of respiratory central pattern generator (CPG) located mainly in the ventrolateral medulla. Excitatory drive to I laryngeal PCA motoneurons, expressing various firing patterns, may come primarily from augmenting (Iaug), less from decrementing (Idec) and constant (Icon)

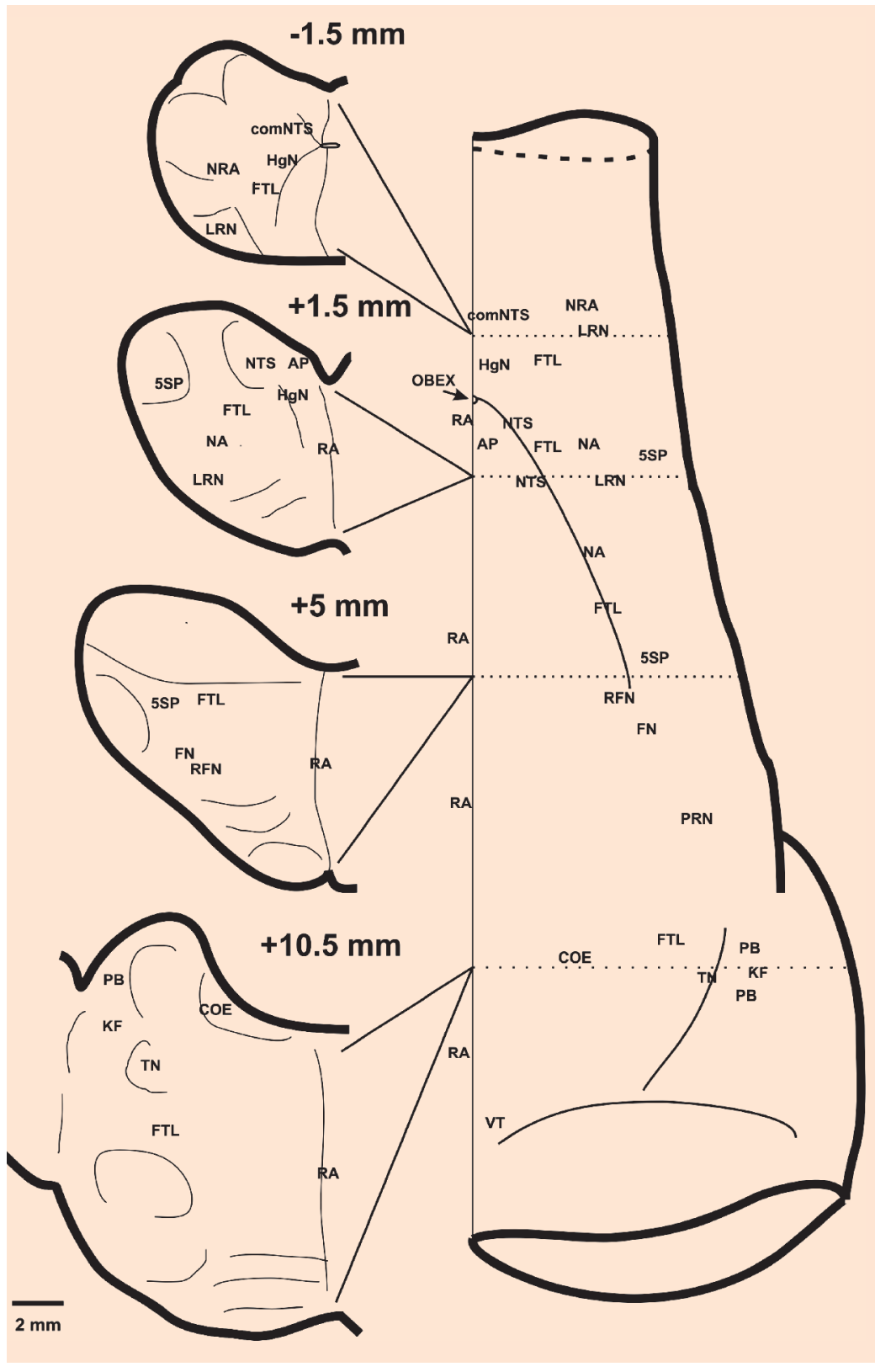

Fig. 4 Scheme of brainstem areas with neurons related to the control of upper airways. The caudal direction is upwards, the position of transverse sections (on the left hand side) relates to the obex. 5SP - spinal trigeminal ncl.; AP - area postrema; COE - coeruleus ncl.; comNTS - commissural subnucleus of NTS; FTL lateral tegmental field; HgN - hypoglossal ncl.; KF Kölliker-Fuse ncl.; LRN lateral reticular ncl.; NA ambigual ncl.; NF - facial ncl.; NRA - retroambigual ncl.; NTS - solitary tract ncl.; PB - parabrachial area; PRN - parvocellular reticular ncl.; RA - raphé; RFN retrofacial ncl.; TN - trigeminal ncl.; VT - ventromedial tegmentum 
I neurons (Baekey et al. 2001; Poliacek et al. 2011). These units increased their firing rate during coughing corresponding to augmented pattern of laryngeal abduction in cough (Baekey et al. 2001; Poliacek et al. 2003) employing additional drive from cough related putatively 2-nd order neurons (O'Connor et al. 2012). E eupneic modulation may arise from the inhibition provided by augmenting (Eaug) and decrementing (Edec) E units. E laryngeal (adductor) motoneurons receive excitatory drive putatively from a subpopulation of Edec laryngeal premotoneurons. Inhibitory connections may arise from various Eaug, Edec, I aug, and Idec neurons (Baekey et al. 2001; Ono et al. 2006; Poliacek et al. 2011; O'Connor et al. 2012). Significant premotoneurons and/or higher order units shaping respiratory laryngeal activity and essential for the development of post-I phase of respiratory cycle are located in Kölliker-Fuse ncl. area of pons (Bautista et al. 2010).

Respiratory control of hypoglossal motoneurons (mainly I activity) is provided via I premotoneurons scattered throughout the lateral tegmental field and interneurons within and near HgN (e.g. Travers and Rinaman 2002; Gestreau et al. 2005). Premotoneurons of HgN motor units are also in the spinal trigeminal nucleus, around ambigual ncl., area of sensory trigeminal ncl., the subcoeruleus region, and the Kölliker-Fuse ncl. (Fay and Norgren 1997; Hayakawa et al. 1999; Peever et al. 2002; Roda et al. 2004). Main respiratory areas of NTS and ventral respiratory group as well as midline raphé may provide distal monosynaptic drive to HgN (and ambigual) motoneurons (Ezure et al. 1993) and/or alternatively they may act as a secondary premotoneurons (Fay and Norgren 1997; Travers and Rinaman 2002; Gestreau et al. 2005). Direct pathway from Kölliker-Fuse area of the pons to the HgN (Hayakawa et al. 1999) is putatively inhibitory (Gestreau et al. 2005).

Consistent with the pattern of several UA muscles during defensive motor behaviors and with the necessity of appropriate coordination with other behaviors (e.g. reciprocal inhibition of I vs. E related motor acts), additional neuronal populations certainly participate in their activation. E.g. PCA receives, besides neuronal drives from aformentioned neurones of respiratory CPG primarily located in the ventrolateral medulla and NTS, inputs from the pons, periaqueductal gray, hypothalamus, amygdala and piriform complex (Waldbaum et al. 2001).

\section{ADDITIONAL CENTRAL COMPONENTS OF UPPER AIRWAY CONTROL}

In addition to aformentioned connections from CPG to laryngeal and pharyngeal motoneurons, working during breathing, coughing, and sneezing (Shiba et al. 1999; Gestreau et al. 2005), modulation of primary cough neuronal network induced variable effects in laryngeal motor output. Elimination of cough motor pattern by lesions in medullary raphé, lateral tegmental field, and pontine parabrachial region mostly preserved the elementary laryngeal adductor responses and respiratory pattern of UA (Poliacek et al. 2005). Elementary laryngeal responses represent functional evidence for multiple axonal pathways and excitatory drives targeting UA motor output. Significant modulation of ventilatory motor output from the retroambigual region, caudal medial reticular formation, or by baroreceptor stimulation induced only limited changes in UA motor pattern during coughing. It suggests shaping of the UA motor output during coughing dependent on the cough CPG. However, it is also consistent with the control of muscle activation (and level of their contraction) largely independent from the motor output of the pump muscles (Poliacek et al. 2003; 2007; 2010; 2011) that likely employs additional pathways than those from CPG (also Shiba et al.1999). However, changes in PCA discharge during coughing concurrent to those in I pump muscles were seen after nicotine administration in the brainstem or in the retroambigual area (Poliacek et al. 2015).

Majority of swallowing-related neurons in the areas of NTS and medullary reticular formation (neither of them were motoneurons) express activation, inhibition, or after-swallow activation. These units project to the NTS, reticular formation, ambigual ncl., HgN, and dor- 
sal motor nucleus of vagus (Sugiyama et al. 2011). Majority of respiratory neurons in the ventrolateral medulla and lateral reticular formation including I neurons and Eaug units are inhibited during swallowing, latter reducing inhibition of $\mathrm{E}$ laryngeal motoneurons and allowing vigorous adductor swallow activation (Chen et al. 1999; Shiba et al. 2007). Many of these neurons may express post-swallow activation (Saito et al. 2003). Thus, Eaug neurons significantly form the motor outputs during breathing, coughing and sneezing, but they do not participate in swallowing (Shiba et al. 2007). Vice versa, the majority of Edec neurons are activated during swallowing (Chen et al. 1999; Saito et al. 2003). Inhibitory interneurons in the parabrachial and trigeminal area of pons putatively drive the pre-motor pathway from Kölliker-Fuse ncl. to the HgN (Getreau et al. 2005).

\section{SYNAPTIC CONTROL OF UPPER AIRWAYS - NEUROTRANSMISSION}

Corresponding to the behavior that is actually executed (breathing, coughing, swallowing etc.), neuronal control system of UA employs number of mediators and neuromodulators that act on a variety neuronal receptors. Abundant connectivity of the neuronal network that controls UA patency employs NMDA, AMPA/kainate receptors (Chen and Travers 2003; Yamazaki et al. 2009), GABA receptors e.g. within reticular formation (Chen et al. 2003; Harada et al. 2005) and pons (Bautista and Dutschmann 2014), opioid receptors (Richardson and Gatti 2005; Hajiha et al. 2009; Yamazaki et al. 2009), nicotinic receptors containing diverse units at various HgN motoneurons (Chamberlin et al. 2002; Dekhordi et al. 2005). Moreover, nicotine administered in the brainstem modulates differently thyroarytenoid and PCA and affects oppositely PCA activity during coughing and breathing (Poliacek et al. 2015). Then, serotoninergic receptors (Brandes et al. 2007) e.g. those in HgN (Volgin et al. 2003) targeting by raphé units (Barker et al. 2009), histamine receptors (Neuzeret et al. 2009), arginine vasopressin receptors involved in respiratory inhibition of HgN neurons (Chuang et al. 2005), and also terminals for substance P (Sun et al. 2003) participate in UA control. Additional enkephalinergic (Bouryi and Lewis 2004), cholinergic (Volgin et al. 2008), glycinergic, tachykinine, catecholamine, and possibly other types of modulation at various neuronal levels is likely present. Irregularities in UA control may result in dysphagia, dystussia and other conditions related to UA functions.

\section{UPPER AIRWAY DISORDERS}

Disorders of UA comprise inflammatory diseases such as rhinitis, pharyngitis, laryngitis, including upper respiratory tract infections, conditions causing stridor and snore, the upper airway resistance syndrome, obstructive sleep apnea / hypopnea syndrome, dysphagia conditions, complications related to gastroesophageal reflux, laryngospasm, etc. UA diseases may result from infections, allergic reactions, anatomical malformations, and functional malfunctions at various levels including the muscle and neurological disorders (such as myositis, myotomy, Myasthenia gravis, poliomyelitis, different levels of paralysis, scleroderma, motoneuron diseases, Parkinson, Alzheimer disease, etc). Depending on severity of the disease inappropriate changes in UA resistance may have significant effect on breathing. Discoordination in UA muscles contraction results in dysphagia or failure of other reflex behaviors (Perlman 2006; Miller 2008; Hammer et al. 2013; Nishino 2013).

Stimulation of UA, resulting in powerful motor behaviors such as cough, sneeze, aspiration reflex etc., has an extensive impact on respiratory and cardiovascular functions. Irregularities in breathing, apnoe, excessive fluctuations in blood pressure and blood flow etc. may occur. However, these changes are not necessarily always negative. E.g. UA stimuli and related reflexes, primarily aspiration reflex, may result in an interruption of apnea and a restoration of breathing, in stabilization and potentiation of respiratory pattern as 
well as cardiac and CNS (arousal) functions. Thus, aspiration reflex, sniff reflex, and other responses from UA might be appropriately employed in reversing various functional disorders and provoking cardio-cerebral resuscitation (Batsel and Lines 1973; Tomori et al. 2012; 2013).

Primarily cholinergic, norepinephrine, and serotonergic tonic drives are implicated in disorders related to reduced UA tone, such as the obstructive sleep apnea (Kuna et al. 1997; Neuzeret et al. 2009). Pharmacological and frequently simple surgical interventions on soft palate and/or palatine uvula may improve these conditions (snore, obturation) in patients (Sawczuk and Mosier 2001). Severe damage (after injuries) is repaired by reconstruction plastic surgery. However, UA surgeries bring the risk of scars and functional irregularities. Recently, besides medicinally treatment, conditional procedures incorporating exercise and practice, stimulation of appropriate (frequently multiple) afferent pathways (Amin and Belafsky 2010; Nishino 2013), and combining various reflex responses (Pitts et al. 2013, Simera et al. 2015) may offer promising therapies at least for certain diseases.

\section{REFERENCES}

1. Amin MR, Belafsky PC. Cough and Swallowing Dysfunction. Otolaryngol Clin N Am 2010; 43: 35-42.

2. Bailey EF, Fregosi RF. Modulation of upper airway muscle activities by bronchopulmonary afferents. J Appl Physiol 2006; 101: 609-17.

3. Baekey DM, Morris KF, Gestreau C, Li Z, Lindsey BG, Shannon R: Medullary respiratory neuronesand control of laryngeal motoneurones during fictive eupnoea and cough in the cat. J Physiol Lond 2001; 534: 565-81.

4. Barker JR, Thomas CF, Behan M. Serotonergic projections from the caudal raphe nuclei to the hypoglossal nucleus in male and female rats. Respir Physiol Neurobiol 2009; 165(2-3): 175-84.

5. Batsel HL, Lines AJ Jr. Bulbar respiratory neurons participating in the sniff reflex in the cat. Exp Neurol 1973; 39(3): 469-81.

6. Bautista TG, Burke PGR, Sun QJ, Berkowitz RG, Pilowsky PM. The Generation of Post-Inspiratory Activity inLaryngeal Motoneurons: a Review. In: Homma I et al., editors. New Frontiers in Respiratory Control, Advances in Experimental Medicine and Biology 669, Springer, 2010. p. 143-49.

7. Bautista TG, Dutschmann M. Ponto-medullary nuclei involved in the generation of sequential pharyngeal swallowing and concomitant protective laryngeal adduction in situ. J Physiol 2014; 592(12): 2605-23.

8. Boers J, Hulshoff AC, DeWeerd H,Mouton LJ, Kuipers R, Holstege G. Afferent Projections to Pharynx and Soft Palate Motoneurons: A Light and Electron Microscopical Tracing Study inthe Cat. J Comp Neurol 2005; 486: 18-38.

9. Bouryi VA, Lewis DI. Enkephalinergic inhibition of raphe pallidus inputs to rat hypoglossal motoneurones in vitro. Neuroscience 2004; 129(1): 55-64.

10. Brancatisano TP, Dodd DS, Engel LA. Responses of the posterior cricoarytenoid and alae nasi muscles to indreased chemical drive in man. Respir Physiol 1986; 64(2): 177-89.

11. Brandes IF, Zuperku EJ, Dean C, Hopp FA, Jakovcevic D, Stuth EA. Retrograde labeling reveals extensive distribution of genioglossal motoneurons possessing 5-HT2A receptors throughout the hypoglossal nucleus of adult dogs. Brain Res 2007; 1132(1): 110-9.

12. Chamberlin NL, Bocchiaro CM, Greene RW, Feldman JL. Nicotinic excitation of rat hypoglossal motoneurons. Neuroscience 2002; 115(3): 861-70.

13. Chen $Z$, Travers SP, Travers JB. Inhibition of licking and the oral phase of rejection by microinjection of lidocaine in the medullary reticular formation. Appetite 1999; 33: 259.

14. Chen Z, Travers JB. Inactivation of amino acid receptors in medullary reticular formation modulates and suppresses ingestion and rejection responses in the awake rat. Am J Physiol Regul Integr Comp Physiol 2003; 285: 68-83.

15. Chuang CW, Cheng MT, Yang SJ, Hwang JC. Activation of ventrolateral medulla neurons by arginine vasopressin via V1A receptors produces inhibition on respiratory-related hypoglossal nerve discharge in the rat. Chin J Physiol 2005; 48(3): 144-54. 
16. Dehkordi O, Millis RM, Dennis GC, Coleman BR, Johnson SM, Changizi L, Ovid Trouth C. Alpha7 and alpha-4 nicotinic receptor subunit immunoreactivity in genioglossus muscle motoneurons.Respir Physiol Neurobiol 2005; 145(2-3): 153-61.

17. Doty RW, Bosma JF. An Electromyographic Deglutition Analysis of Reflex deglutition. J Neurophysiol 1956; 19: 44-60.

18. Ertekin C, Aydogdu I. Neurophysiology of swallowing. Clin Neurophysiol 2003; 114(12): 2226-44.

19. Ezure K, Oku Y, Tanaka I. Location and axonal projection of one type of swallowing interneurons in cat medulla. Brainn Res 1993; 632: 216-24.

20. Fay RA, Norgren R. Identification of rat brainstem multisynaptic connections to the oral motor nuclei using pseudorabiesvirus. III. Lingual muscle motor systems. Brain Res Rev 1997; 25: 291-311.

21. Gestreau C, Grélot L, Bianchi AL. Activity of respiratory laryngeal motoneurons during fictive coughing and swallowing. Exp Brain Res 2000; 130: 27-34.

22. Gestreau C, Dutschmann M, Obled S, Bianchi AL. Activation of XII motoneurons and premotor neurons duringvarious oropharyngeal behaviors. Respir Physiol Neurobiol 2005; 147: 159-76.

23. Hairston LE, Sauerland EK. Electromyography of the human palate: discharge patterns of the levator and tensor veli palatini. Electromyogr Clin Neurophysiol 1981; 21(2-3): 287-97.

24. Hajiha M, DuBord MA, Liu H, Horner RL. Opioid receptor mechanisms at the hypoglossal motor pool and effects on tongue muscle activity in vivo. J Physiol 2009; 587(Pt 11): 2677-92.

25. Hammer MJ, Murphy CA, Abrams TM. Airway Somatosensory Deficits and Dysphagia in Parkinson's Disease. J Parkinsons Dis 2013; 3(1): 39-44.

26. Harada H, Takakusaki K, Kita S, Matsuda M, Nonaka S, Sakamoto T. Effects of injecting GABAergic agents into the medullary reticular formation upon swallowing induced by the superior laryngeal nerve stimulation in decerebrate cats. Neurosci Res. 2005; 51(4): 395-404.

27. Hayakawa T, Zheng JQ, Seki M. Direct parabrachial nuclear projections to the pharyngeal motoneurons in the rat: an anterograde and retrograde double-labeling study.Brain Res. 1999; 816(2):364-74.

28. Iscoe SD. Central control of the upper airway. In: Mathew OP, Sant'Ambrogio G, editors.Respiratory Function of the Upper Airway, Lung Biology in Healthand Disease. New York: Marcel Dekker; 1988. p. 125-92.

29. Jakus J, Tomori Z, Stransky. Neuronal determinants of breathing, coughing and related motor behaviours. Martin: Wist; 2004. 334 p.

30. Jakus J, Poliacek I, Halasova E, Murin P, Knocikova J,Tomori Z, Bolser DC. Brainstem circuitry of tracheal-bronchial cough: c fos study in anesthetized cats. Respir Physiol Neurobiol 2008; 160: 289-300.

31. Jean A. Brain Stem Control of Swallowing: Neuronal Network and Cellular Mechanisms. Physiol Rev 2001; 81(2): 929-69.

32. Korpáš J, Tomori Z. Cough and other respiratory reflexes. Basel: Karger S; 1979. 356 p.

33. Kuna ST, Smickley JS. Superior pharyngeal constrictor activation in obstructive sleep apnea. Am J Respir Crit Care Med 1997; 156: 874-80.

34. Mezzanotte WS, Tangel DJ, White DP. Mechanisms of control of alae nasi muscle activity. J Appl Physiol (1985) 1992; 72(3): 925-33.

35. Miller AJ. The neurobiology of swallowing and dysphagia. Dev Disabil Res Rev 2008; 14:77-86.

36. Neuzeret PC, Sakai K, Gormand F, Petitjean T, Buda C, Sastre JP, Parrot S, Guidon G, Lin JS. Application of histamine or serotonin to the hypoglossal nucleus increases genioglossus muscle activity across the wake-sleep cycle. J Sleep Res 2009; 18(1): 113-21.

37. Nishino T. The swallowing reflex and its significance as an airway defensive reflex. Front Physiol 2013; 3: 489: 1-6.

38. O'Connor R, Segers LS, Morris KF, Nuding SC, Pitts TE, Bolser DC, Davenport PW, Lindsey BG. A joint computational respiratory neural network-biomechanical model for breathing and airway defensive behaviors. Front Physiol 2012; 3(264): 1-28.

39. Ono K, Shiba K, Nakazawa K, Shimoyama I. Synaptic Origin of the Respiratory-modulated Activity of Laryngeal Motoneurons. Neurosci 2006; 140: 1079-88.

40. Peever JH, Shen L, Duffin J. Respiratory pre-motor controlof hypoglossal motoneurons in the rat. Neurosci 2002; 110: 711-22.

41. Perlman AL. Electromyography in oral and pharyngeal motor disorders. GI Motility online 2006; doi: $10.1038 /$ gimo32. 
42. Pitts T, Rose MJ, Mortensen AN, Poliacek I, Sapienza CM, Lindsey BG, Morris KF, Davenport PW, Bolser DC. Coordination of cough and swallow: A meta-behavioral response to aspiration. Respir Physiol Neurobiol 2013; 189(3): 543-51.

43. Pitts T, Rose MJ, Poliacek I, Condrey J, Davenport PW, Bolser DC. Effect of laparotomy on the swallow-breathing relationship in the cat. Lung 2015; 193(1): 129-33.

44. Poliaček I, Stránsky A, Jakuš J, Baráni H, Tomori Z, Halašová E. Activity of the Laryngeal Abductor and Adductor Muscles during Cough, Expiration and Aspiration Reflexes in Cats. Physiol Res 2003; 52(6): 749-62.

45. Poliaček I, Stránsky A, Szereda-Przestaszewska M, Jakuš J, Baráni H, Tomori Z, Halašová E. Cough and laryngeal muscle discharges in brainstem lesioned anesthetized cats. Physiol Res 2005; 54(6): 645-54.

46. Poliaček I, Corrie LW, Wang C, Rose MJ, Bolser DC. Microinjection of DLH into the region of the caudal ventral respiratory column in the cat: evidence for an endogenous cough-suppressant mechanism. J Appl Physiol 2007; 102(3): 1014-21.

47. Poliacek I, Wang C, Corrie LW-C, Rose MJ, Bolser DC. Microinjection of Codeine into the Region of the Caudal Ventral Respiratory Column Suppresses Cough in Anesthetized Cats. J Appl Physiol 2010; 108: 858-65.

48. Poliaček I, Jakuš J, Halašová E, Baráni H, Muríň P, Bolser DC. Defensive airways reflexes induce widely spreading Fos labeling in the cat brainstem. Acta Med Mart 2008; 8(2): 3-15.

49. Poliacek I, Morris KF, Lindsey BG, Segers LS, Rose MJ, Corrie LW, Wang C, Pitts TE, Davenport PW, Bolser DC. Blood pressure changes alter tracheobronchial cough: computational model of the respiratory-cough network and in vivo experiments in anesthetized cats. J Appl Physiol 2011; 111: 861-73.

50. Poliacek I, Rose MJ, Pitts TE, Mortensen A, Corrie LW, Davenport PW, Bolser DC. Central administration of nicotine suppresses tracheobronchial cough in anesthetized cats. J Appl Physiol (1985) 2015; 118(3): 265-72.

51. Richardson KA, Gatti PJ. Genioglossal hypoglossal muscle motoneurons are contacted by nerve terminals containing delta opioid receptor but not mu opioid receptor-like immunoreactivity in the cat: a dual labeling electron microscopic study. Brain Res 2005; 1032(1-2): 23-9.

52. Roda F, Gestreau C, Bianchi AL. Discharge patterns of hypoglossal motoneurons during fictive breathing, coughing, and swallowing. J Neurophysiol 2002; 87: 1703-11.

53. Roda F, Pio J, Bianchi AL, Gestreau C. Effects of anesthetics on hypoglossal nerve discharge and c-Fos expression inbrainstem hypoglossal premotor neurons. J Comp Neurol 2004; 468: 571-86.

54. Rose M, Pitts T, Poliacek I, Mortensen A, Davenport P, Bolser D. Activity of the upper esophageal sphincter (UES) during eupnea, cough, and swallow. FASEB J 2011; 25(1 Suppl): 1111.21.

55. Saboisky JP, Butler JE, McKenzie DK, Gorman RB, Trinder JA, White DP, Gandevia SC. Neural drive to human genioglossus in obstructive sleep apnoea. J Physiol 2007; 585(1): 135-46.

56. Saito Y, Ezure K, Tanaka I, Osawa M. Activity of neurons in ventrolateral respiratory groups during swallowing in decerebrate rats. Brain Dev 2003; 25(5): 338-45.

57. Sant'Ambrogio G, Kuna ST, Vanoye CR, Sant'Ambrogio FB. Activation of intrinsic laryngeal muscles during cough. Am J Respir Crit Care Med 1997; 155: 637-41.

58. Satoh I, Shiba K, Kobayashi N, Nakajima Y, Konno A. Upper airway motoroutputs during sneezing and coughing in decerebrate cats. Neurosci Res 1998; 32(2): 131-5.

59. Sawczuk A, Mosier KM. Neural control of tongue movement with respect to respiration and swallowing.Crit Rev Oral Biol Med 2001; 12(1): 18-37.

60. Sherrey JH, Megirian D. Spontaneous and reflexly evoked laryngeal abductor and adductor muscle activity of cat. Exp Neurol 1974; 43: 487-98.

61. Shi YX, Seto-Poon M, Wheatley JR. Breathing route dependence of upper airway muscle activity during hyperpnea. J Appl Physiol 1998; 84(5): 1701-6.

62. Shiba K, Satoh I, Kobayashi N, Hayashi F. Multifunctional Laryngeal Motoneurons: an Intracellular Study inthe Cat. J Neurosci 1999; 19(7): 2717-27.

63. Shiba K, Nakazawa K, Ono K, Umezaki T. Multifunctional Laryngeal Premotor Neurons: Their Activities during Breathing, Coughing, Sneezing, and Swallowing. J Neurosci 2007; 27(19): 5156 -62.

64. Simera M, Poliacek I, Dobrolubov B, Veternik M, Plevkova J, Jakus J. Interactions of mechanically induced coughing and sneezing in cat. Respir Physiol Neurobiol 2015; 205: 21-7.

65. Spearman DG, Poliacek I, Rose MJ, Bolser DC, Pitts T. Variability of the pharyngeal phase of swallow in the cat. PLoS One 2014; 9(8): e106121. 
66. Stránsky A., Szereda-Przestaszewska M., Widdicombe J.G., Tomori Z. The activity of laryngeal motoneurons and laryngeal resistance during defensive reflexes from the respiratory tract. Physiol Bohemoslov 1976; 25: 471.

67. Sugiyama Y, Shiba K, Nakazawa K, Suzuki T, Umezaki T, Ezure K, Abo N, Yoshihara T, Hisa Y. Axonal projections of medullary swallowing neurons in guinea pigs. J Comp Neurol. 2011; 519(11): 2193-211.

68. Sun Q, Berkowitz R, Goodchild A, Pilowsky P. Substance P inputs to laryngeal motoneurons in the rat. Respir Physiol Neurobiol 2003; 137(1): 11-8.

69. Suzuki Takeshi, Nakazawa K, Shiba K. Swallow-related inhibition in laryngeal motoneurons. Neurosci Res 2010; 67: 327-33.

70. Tomori Z, Donic V, Benacka R, Gresova S, Peregrim I, Kundrik M, Pallayova M, Jakus J. Reversal of functional disorders by aspiration, expiration, and cough reflexes and their voluntary counterparts. Front Physiol 2012; 3: 467.

71. Tomori Z, Donic V, Benacka R, Jakus J, Gresova S. Resuscitation and auto resuscitation by airway reflexes in animals. Cough 2013; 9: 21.

72. Travers JB, Rinaman L. Identification of lingual motor controlcircuits using two strains of pseudorabies virus. Neurosci 2002; 115: 1139-51.

73. Van Lunteren E, Strohl KP. The muscles of the upper airways. Clin Chest Med 1986; 7(2): 171-88.

74. Waldbaum S, Hadziefendic S, Erokwu B, Zaidi SIA, Haxhiu MA. CNS innervation of posterior cricoarytenoid muscles: a transneuronal labeling study. Respir Physiol 2001; 126: 113-25.

75. Volgin DV, Fenik VB, Fay R, Okabe S, Davies RO, Kubin L. Serotonergic Receptors and Effects in Hypoglossal and Laryngeal Motoneurons Semi-Quantitative Studies in Neonatal and Adult Rats. Adv Exp Med Biol 2003; 551: 183-8.

76. Volgin DV, Rukhadze I, Kubin L. Hypoglossal premotor neurons of the intermediate medullary reticular region express cholinergic markers. J Appl Physiol 2008; 105(5): 1576-84.

77. Yamazaki H, Ohi Y, Haji A. Mu-opioid and N-methyl-D-aspartate receptors are localized at laryngeal motoneurons of guinea pigs. Biol Pharm Bull 2009; 32(2): 293-6.

78. Zoungrana OR, Amri M, Car A, Roman C. Intracellular activity of motoneurons of the rostral nucleus ambiguus during swallowing in sheep. J Neurophysiol 1997; 77: 909-22.

\section{Acknowledgment:}

This work was supported by the Slovak Research and Development Agency under the contract No. APVV-0189-11“, by VEGA No. 1/0126/12, 1/0253/15 and project Center of Experimental and Clinical Respirology (CECR II) ITMS: 26220120034. We support research activities in Slovakia / Project is co-financed by EU sources.

Received: April, 13, 2016

Accepted: April, 24, 2016 